\title{
Multilevel embeddedness in multilateral alliances: A conceptual framework
}

\author{
Sveinn Vidar Gudmundsson \\ Christian Lechner \\ Toulouse Business School, France \\ 20, Boulevard Lascrosses \\ 31068 Toulouse Cedex \\ France \\ phone: +33 (0)534 660892 \\ Hans van Kranenburg \\ Radboud University Nijmegen \\ Institute for Management Research \\ Nijmegen School of Management \\ P.O. Box 9108, 6500 HK Nijmegen, \\ The Netherlands \\ phone: +31(0)24 3612028
}




\section{Multilevel embeddedness in multilateral alliances: A conceptual framework ${ }^{1}$}

\section{Sveinn Vidar Gudmundsson, Christian Lechner, and Hans van Kranenburg}

In this chapter we propose a conceptual framework for understanding of inter-partner dynamics in multilateral alliances involving common alliance processes, dyadic ties, and external transaction networks. The difference between alliance networks and multilateral alliances is the formalization of organization and common alliance processes in the latter. The firm-specific value in multilateral alliances is often buried in dyadic ties, that can be the prime motivator to join in the first place, but at the same time hindering common alliance processes. This multiplexity of relations, multilevel embeddedness, is both a source of strategic constraints and opportunities. Multilateral alliances set firms heading towards increased rigidity, cooperation and long-term orientation, requiring careful management of rising exit barriers to preserve strategic flexibility.

\section{INTRODUCTION}

Alliance relations are institutional arrangements in which transactions take place (Richardson, 1972; Lomi, 1995). They constitute a transaction sphere that is an alternative governance mode to market transactions and vertical integration (Richardson, 1972). Alliances have

\footnotetext{
${ }^{1}$ Cite as:

GUDMUNDSSON, S.V., LECHNER, C. and Van KRANENBURG, H. (2012) Multilevel embeddedness in multilateral alliances: A conceptual framework. In: Das, T.K. Research in Strategic Alliances Series: Interpartner Dynamics in Strategic Alliances. Information Age Publishing, USA (forthcoming)
} 
commonly been formed among two firms, a dyad, but increasingly by a block of firms, an alliance network (Doz \& Hamel, 1998; Gomes-Casseres, 1996; Lazzarini, 2007;

Vanhaverbeke \& Noorderhaven, 2001). The literature draws up a picture of alliance networks and constellations clustering around a focal firm or a focal project (Das \& Teng, 2002; Doz \& Hamel, 1998; Vanhaverbeke \& Noorderhaven, 2001), while our definition of multilateral alliances (MLA) is formalized multi-partner inter-firm relations that involve not only a collection of dyads, but also central organization and common alliance processes.

Doz and Hamel (1998, p.221) suggest that firms engaged in multilateral alliances are "entangled in a complex web of interdependent relationships that tax their strategic cleverness and managerial skills." One way to understand the "complex web" is by engaging embeddedness theory. We understand inter-firm relations as a complex set of relations influencing and influenced by society they are embedded in. Embeddedness theory (Granovetter, 1985) helps to understand how networks of relations discourage mischief and influence choices through past interactions. Researchers have extended this work in various contexts such as cross-level embeddedness and overembeddedness (Hagedoorn, 2006; Hagedoorn \& Frankort, 2008). Most of this research has focused on the influence of embeddedness on alliance formation but less on its influence on alliance dynamics.

In alliance networks when there is an advantage in connecting resources through common processes and standards, a central organization needs to be formed due to the relational complexity. With formal organization, closure (Coleman, 1988) takes place, at the same time that dyadic relations continue to exist both internal and external to MLA. Instead of viewing MLA as replacing dyadic relations it can be seen as creaming the cake, an additional set of strong ties on top of the existing relations, a mix of network closure (Coleman, 1988) and exploitation of structural holes (Burt, 2001). However, little research exists on the benefits of 
closure and structural holes in combination on one and the same alliance (Burt, 2001; Gudmundsson \& Lechner, 2006).

Our objective in this chapter is to explore the important question of how multilevel embeddedness influences MLA tensions, the exploitation of opportunities and how perceived barriers to exit influence the entry decision. We start by discussing definitions of different forms of multi-partner alliances and particularly MLA, we then proceed to the theoretical perspectives that can be used to explain the multiplexity of MLA, we develop several propositions around our conceptual framework, and finally discuss the implications of our work.

\section{DEFINING MULTILATERAL ALLIANCES}

A body of research has examined alliance networks, alliance constellations and MLA (Das \& Teng, 2002; Doz \& Hamel, 1998; Gomes-Casseres, 1996; Gudmundsson \& Lechner, 2006; Lazzarini, 2008; Vanhaverbeke \& Noorderhaven, 2001). For sake of clarity in the remainder of this chapter we have listed definitions and the corresponding references in Table 1 to demonstrate how these three concepts have evolved.

Table 1 about here

Lazzarini (2008) argues that the term alliance constellation (Das \& Teng, 2002; GomesCasseres, 1996) has been used to denote both alliance networks and multilateral alliances and the two are not the same. A perspective from technology and software industries is likely to see a focal firm at the centre of alliance relations or a single project into which all the firms are linked. Such as the RISC (project) processor alliance described by Vanhaverbeke and Noorderhaven (2001) or Fujitsu (focal firm) mainframe computer alliance described by Doz and Hamel (1998). Such alliances are inherently short-term as the project either fails or is 
completed. This brings up the question if constellations are more about projects and focal firms rather than a more permanent configuration of alliance relations. We could denote constellations as a ring of firms that constantly rearrange relations around projects and add or shed participants with redundant ties. These configurations are common in many industries including software and aerospace. However, permanent alliance arrangements are rarer such as we find in the airline industry (oneworld, Skyteam and STAR) where the project is the alliance itself a long-term vision of commonalities, but without any fixed completion time after which the partners rearrange within the alliance network. These arrangements are frequently found in network industries and services where interlinking of rights networks (legal operational boundaries) and the use of common standards are important.

We like to draw a line between constellations that describe project or focal firm focused alliance networks having some formal arrangements between all partners, and MLA where formal arrangements are not project or focal firm focused and are not rearranged upon completion of projects. In other words a constellation and MLA are not the same, but both constitute a group of firms that compete with other groups of firms. Our work focuses on multilateral alliances with central organization so we favour the term multilateral alliance (MLA) rather than constellation to underline a difference.

\section{THEORETICAL PERSPECTIVES}

To understand the multiplexity of MLA it is necessary to engage several theoretical perspectives: tensions perspective (Das \& Teng, 2000; De Rond \& Bouchikhi, 2004), social network theory (Burt, 1992; Coleman, 1988; 1990), and embeddedness perspective (Granovetter, 1985). We cover each of these theoretical perspectives to unravel their significance in explaining MLA dynamics. 


\section{Tensions Perspective}

The dynamism of relations within MLA can be understood using a tensions perspective (Das $\&$ Teng, 2000). The tensions perspective sees alliances being subject to competing forces across three spectrums: cooperation versus competition; rigidity versus flexibility; and shortterm versus long-term.

Competition is defined (Das \& Teng, 2000, p. 85) "as pursuing one's own interest at the expense of others" and cooperation "is the pursuit of mutual interests and common benefits." In MLA a stronger opportunistic focal firm may attempt to contribute fewer resources and control more of the alliance benefits. In MLA where one firm is larger than the rest or is financially superior, opportunistic self-interest can develop and overtake cooperation. Since cooperation and competition are opposing forces an imbalance must be resolved (Das \& Teng, 2000; Gudmundsson, 2011). Too much competition will see one partner seek to internalize the gains and unique resources of other partners (Khanna, Gulati, \& Nohria, 1998; Yoshino \& Rangan, 1995) or to control their actions. However, MLA can be considered to move along a continuum from competition to cooperation and balance the tension between competition and cooperation. Too much competition due to high density in MLA will cause the exit of partners with redundant ties, whilst too much cooperation in MLA will lead to lock-in, strategic constraints and eventually a merger of inseparable firms (Gudmundsson \& Lechner, 2011). ${ }^{2}$

Rigidity (Das \& Teng, 2000, p. 86) is defined "in terms of the degree of connectedness of members with each other in an ongoing relationship." While flexibility is an opposing force, freedom of action or loose coupling, is usually considered integral to alliance formation. Firms start alliances opposed to mergers to retain flexibility. Flexibility allows faster realignment of resources to take advantage of opportunities, but rigidity reduces coordination

\footnotetext{
${ }^{2}$ One can also see the possibility of a domino effect if one partner declares bankruptcy other closely tied partners face the same fate unless the bankrupt firm is overtaken or merged to salvage common assets.
} 
costs through stability and greater cohesion. From the perspective of the social network theory firms should focus on opportunities generated by structural holes, but exercise a degree of closure to realize the value buried in the holes (Burt, 2001). This is best accomplished in a multilateral alliance by balancing flexibility and rigidity. MLA increase rigidity as the connectedness among partners increases and cohesion through control escalates. The formalization of the MLA through a central organization increases rigidity and relational trust by regulating opportunistic behavior. The tension associated with too much rigidity, becoming tangled in one's own web, or over-embedded (Hagedoorn \& Frankort, 2008), poses a real paradox for MLA partners, reinforcing their desire to balance rigidity and flexibility.

The third tension is between short-term and long-term orientation. The MLA by nature of its central organization and required upfront investment pushes firms to take the long-view upon joining MLA. The more relational features there are in the MLA the greater the relations-specific investment, the stronger the long-term orientation of the alliance. The directional arrows in Figure 1 show the movement along the three tensions when firms enter MLA. Upon entry to MLA, partners move in certain directions all of which increase the likely duration of attachment (Gudmundsson, 2011). However, this does not exclude the possibility of imbalance leading to instability. There is tension between common benefits and specific benefits and MLA is likely to move towards too much rigidity, too much cooperation, and lock-in, unless managers maintain balance. MLA is no different from any other type of alliance when it comes to exploiting opportunities, to leverage unique resources to the maximum, and to maintain enough strategic flexibility to exit if needed.

Figure 1 about here 


\section{Social Network Theory}

We draw parallel between social network theory (Barnes, 1954; Burt, 1992; Granovetter, 1973) and network opportunities and constraints, to explain the link between MLA processes, the pursuit of opportunities, and structural holes and closure (Burt, 2001). Alliance processes can be described as the effective strengthening of alliance ties along a continuum between strong and weak ties (Granovetter, 1973). In the language of social network theory a structural-hole (Burt, 1992; 2001) represents an opportunity, un-served sphere that can be exploited by brokering connections between actors. The theory has been applied to alliance networks that have weak ties and lack central organization. A central position in a network is not the same as central organization in MLA that resembles rather network closure (Coleman, 1988). Little research exists that explains networks having traits of both closure and structural holes (Burt, 2001; Gudmundsson \& Lechner, 2006). This poses a particularly interesting dynamics as firms can access opportunities embedded in structural holes across various levels and varying relational intensities within the boundaries of a single MLA. Such group of firms is embedded in a closed network of common alliance processes with central organization, embedded in an alliance network of dyadic alliances (within the closed network), and the closed network in its entirety is embedded in the sum of all external transaction relations of the partner firms.

In MLA each partner occupies a central position characterized by weak to strong ties. The strong ties represent closure (Coleman, 1988) and the weak ties structural holes (Burt, 1992). Whereas strong ties represent high interaction, information flows and mutual knowledge, they also imply greater redundancy as unique qualities are absorbed or suppressed by the group. Weak ties imply brokerage between unconnected positions in the network and "the less one's contacts know and interact with each other, the more likely the information and knowledge 
available to these contacts will be non-redundant" (Moran, 2005, p. 1132). In other words we can visualize each MLA partner as a doorkeeper between the inner and the outer world of inter-firm relations. When managing the MLA it is essential to keep the door open to both worlds and connect them to maintain constant stream of information about new opportunities.

\section{Embeddedness Theory}

An embeddedness perspective (Baum \& Dutton, 1996; Dacin, Ventresca \& Beal, 1999; Granovetter, 1985; Polanyi, 1944) suggests that firms' actions are constrained on one hand by resource endowments and on the other hand by a network of relations. The concept of embeddedness in social networks comes from the simple observation that "most behavior is closely embedded in networks of inter-personal relations" (Granovetter, 1985, p. 504). The literature has examined the existence of embedded relations and how they create competitive advantage for firms and networks of firms (Granovetter, 1995; Gulati, 1995; Uzzi, 1997). Uzzi (1999: 482) defined embeddedness “....as the degree to which commercial transactions take place through social relations and networks of relations that use exchange protocols associated with social, non-commercial attachments to govern business dealings." Alliance embeddedness, therefore, implies that actors are embedded in a network of enduring and repeated relations (Baum \& Dutton, 1996; Burt, 1992; Dacin, Ventresca \& Beal, 1999; Granovetter, 1992, 1985; Lomi, 1995).

The relational, positional, and structural constitute the usual embeddedness types considered to influence alliances (Gulati \& Gargiulo, 1999). Relational embeddedness symbolizes cohesive ties between actors that channel information about capabilities and abilities of others (Gulati \& Gargiulo, 1999). Cohesive ties build trust, transparency and reduce uncertainty in existing and future partnerships (Burt and Knez 1995; Podolny 1994). Positional embeddedness stands for positional impact of the organization in the overall 
alliance network structure and decisions over new ties (Gulati \& Gargiulo, 1999). This type of embeddedness encapsulates the system roles actors occupy (Borgatti \& Everett, 1994; Faust, 1988; Winship \& Mandel, 1983). Structural embeddedness symbolizes the influence of relations around actors on their propensity to form relations with others (Granovetter, 1992; Gulati \& Gargiulo, 1999). This type of embeddedness shifts the focus to groups of actors and to informal information channels (Gulati \& Gargiulo, 1999).

Hagedoorn (2006) suggests that embeddedness traverses several levels depending on the social context surrounding partnerships: environmental, interorganizational, and dyadic. Overembeddedness takes place when actors are entrenched in their relational environment facing a reduced pool of potential new partners (Hagedoorn, 2006).

Based on the theoretical concepts we have covered so far in the chapter we have the building blocks to conceptualize the structure and dynamics inherent in MLA. In the section that follows we put forward a framework for MLA and offer several derived propositions.

\section{A CONCEPTUAL FRAMEWORK OF MLA}

Firms engaged in MLA are embedded in inter-firm relations on multiple levels as shown in Figure 2. In the figure solid lines denote relations links among firms $\boldsymbol{A}$ through $\boldsymbol{X}_{\mathrm{i}}$, engaged in MLA. The broken lines denote relations links outside MLA, whereas the dotted rings show shared spheres, and solid rings denote proprietary (ego) spheres. $\boldsymbol{E}$ denotes alliance relations within the MLA; and $\boldsymbol{E}_{\boldsymbol{A} \boldsymbol{B} \boldsymbol{C} \boldsymbol{X} \mathbf{i}}(\mathbf{i}=1 \ldots . . \boldsymbol{n}$, partners, where $\boldsymbol{n}>2)$ denotes a common sphere shared among all partners; $\boldsymbol{E}_{\boldsymbol{A} \boldsymbol{B}} \ldots \boldsymbol{E}_{\boldsymbol{C X} \mathbf{i}}$, denote dyadic shared spheres within MLA. Dyadic links $\boldsymbol{E}_{\boldsymbol{A} \boldsymbol{C}}$, and $\boldsymbol{E}_{\boldsymbol{B X}}$ are omitted to symbolize absence of structural holes between some partners, i.e. all possible links will never be exploited. And $\boldsymbol{e}$ denotes proprietary transaction

partners; $\boldsymbol{e}_{\mathbf{a}}{ } \ldots \boldsymbol{e}^{\prime}{ }_{x \mathbf{i}}$ denote proprietary transaction partners shared in the alliance; $\boldsymbol{e}_{\boldsymbol{A}} \ldots \boldsymbol{e}_{\boldsymbol{X} \mathbf{i}}$, denote proprietary transaction partners not shared. Each relations layer is embedded $(\subseteq=$ 
subset of $)$ in another until we reach the set of all possible relations in society $\left(\boldsymbol{E}^{\prime} \subseteq \boldsymbol{E} \subseteq(\boldsymbol{e}+\right.$ $\left.\boldsymbol{e}^{\prime}\right) \subseteq$ society). Interaction effects between MLA layers become more complex as the relations set becomes larger, but the intensity of relations becomes stronger as the relations set becomes smaller.

Figure 2 about here

Table 2 about here

\section{Alliance Tensions and Proprietary Assets}

The sharing of proprietary assets in MLA can create an exit barrier if firms fear that ownership or uniqueness of the assets will become indistinct due to common alliance processes. ${ }^{3}$ Thus, the propensity to enter MLA increases if proprietary assets are either not shared at all or ring-fenced before sharing takes place. Ring-fencing means setting clear use and ownership rules, e.g. who owns new or promiscuous customers?

Lazzarini (2008) argued that firms with extensive outside ties would have less commitment to MLA and sparseness would increase investment in formalization. We, however, argue that it is not the size of the external network that matters but the degree to which MLA partners can build and control proprietary assets embedded in the external network. Selective sharing may strengthen MLA by balancing the tensions between flexibility and rigidity, cooperation and competition, increasing partner's commitment to low intensity common alliance processes. In this regard there must be a clear distinction between, on one hand, commitment to MLA in its entirety, and on the other hand, commitment to common alliance processes. We can assume that the attraction of new partners to MLA depends on potential exit costs. Since surprises are possible in any alliance, transaction

\footnotetext{
${ }^{3}$ This was demonstrated when Austrian Airlines left Qualiflyer for Star Alliance and had no FFP program on its own as Qualiflyer had merged all into one. Although each airline may have ownership of customer data records other MLA airlines could theoretically access those records after any one airline leaves the alliance.
} 
networks and any unique resources need to be protected and tensions balanced. ${ }^{4}$ Going to the extreme, being too cooperative, straight-jackets the firm, and leads to lock-in. A firm may want such an outcome, but that would be an exception rather than a rule. ${ }^{5}$

Multiple centers of gravity in MLA create opportunities for partners to mix or match resources, to exploit structural holes. Partners do not only exploit structural holes in the common sphere $\left(\boldsymbol{E}_{\mathrm{ABCXi}}\right)$ but also in various dyadic spheres $\left(\boldsymbol{E}_{\mathrm{AB}} \ldots \boldsymbol{E}_{\mathrm{CXi}}, \boldsymbol{e}_{\mathrm{a}} \ldots \boldsymbol{e}_{\boldsymbol{x i}}, \boldsymbol{e}_{\mathrm{A}} \ldots \boldsymbol{e}_{\mathrm{Xi}}\right)$. Shared spheres denote bridging of structural holes, exploitation of opportunities enabled by each partner's unique resources. The ability to exploit various relational spheres within MLA balances alliance tensions (Das \& Teng, 2000), containing potential instability. A MLA only focusing on the common sphere $\left(\boldsymbol{E}_{\mathrm{ABCXi}}\right)$ would be considered too rigid and cooperative. Likewise MLA focusing only on the dyadic spheres and neglecting the common sphere would be considered too flexible and competitive.

Research has shown that the extensiveness of alliance features (number of different resources joined together between the various partners) increases duration (Gudmundsson, 2011; Gudmundsson \& Rhoades, 2001). ${ }^{6}$ In other words MLA containing many relational spheres embedded over several levels is a quintessence of balancing tensions. In MLA the flexibility to enter and exit external and internal dyadic spheres in the pursuit of opportunities enhances partners' ability to develop and maintain competitive advantage. ${ }^{7}$ Thus, MLA

\footnotetext{
${ }^{4}$ Small alliance groupings with limited opportunities EQA, Atlantic Excellence, Global Excellence, and Qualiflyer Group all collapsed because key members defected to competing groupings with larger membership and grander global vision. The first three had limited coverage and the last one was dense employing an equity investment strategy in partners to retain control and prevent defection.

${ }^{5}$ This would probably have been the outcome if the Alcazar project had come about, a 1993 proposal to tie-up and then merge Austrian Airlines, KLM, Scandinavian Airlines System (SAS) and Swissair. The first known merger from within MLA (oneworld) was the merger between British Airways and Iberia.

${ }^{6}$ Having experienced a collapse of previous alliances by defecting partners, Swissair wanted to prevent this happening in their Qualiflyer Group by taking equity investment in all the partners. This strategy ran the company to the ground and failed to build a globally attractive alliance, which type, the previous partners defected to.

${ }^{7}$ The largest most disperse multilateral airline alliance STAR has had turnover of up to 55 percent higher per employee compared to the next MLA. Being concerned about network linkages and passenger flow potentials STAR had also about 40 percent more passengers per employee compared to the next MLA. STAR alliance has also the highest market share on three key transcontinental corridors out of four: Europe-Asia Pacific; NAmerica-Asia; and Europe-N-America.
} 
partners should enter and exit external and internal dyadic spheres more freely in the pursuit of opportunities than in a common sphere.

Proposition 1a. Partners engaged in MLA liberated to exploit multilevel embedded relational spheres, perceive more balance between competition and cooperation, and are less likely to defect (long-term orientation).

Proposition 1b. Partners engaged in MLA sharing fewer assets in the common sphere and more assets in dyadic spheres, perceive more balance between rigidity and flexibility, and are less likely to defect (long-term orientation).

Proposition 1c. Partners engaged in MLA liberated to exploit multilevel embedded relational spheres, entering and exiting external and internal dyadic spheres in the pursuit of opportunities, are more likely to enjoy competitive advantage, and are less likely to defect (long-term orientation).

\section{Structural Holes, Network Position and Partner Variety}

McEvily and Zaheer (1999) pointed out that a network with a high ratio of structural holes can be a source of competitive advantage by providing ideas, knowledge and opportunities: we draw parallel with this analogy. Thus, the higher the ratio of non-redundant ties within MLA, the more value creating is the overall alliance for firms in central positions (Burt, 1992; Granovetter, 1974, 1985) and for partners having non-central but valuable positional assets attractive to bridge structural holes. The position of an actor within an alliance is an opportunity or a constraint. The more central an actors' position the greater the ability to exploit opportunities (Burt, 1992). 
We draw parallel with recent organization and management related studies of networks emphasizing that some network positions generate fewer constraints than others and better access to information and resources (Burt, 1992; Salancik, 1995). Firms can aim to maximize non-redundant ties by entering partners with non-redundant ties and exit partners with redundant ties: The greater the number of partners with largely redundant ties the more intensive the competition between partners e.g. for the same customers. The more nonoccupied structural holes within a network, the greater the positional strength of partners possessing such opportunities. Leading us to conclude that from an ego perspective firms should maximize positional strength in MLA even if that means defection and occasional rearrangement between different MLA. Therefore, partner variety rather than partner homogeneity matters. To put it differently, MLA with high degree of partner variety has structural holes best exploited through flexible dyadic spheres. Likewise partners lacking variety, having many redundant ties, may have positional strength in another MLA. These dynamics may facilitate MLA processes by generating superior firm-specific and customer value.

If benefits can be derived from complementary assets that are inaccessible outside the dyad, it strengthens ties. Strong ties are characterized by frequency and duration of interaction leading to sharing and exchanging of important resources (Lomi, 1997). However, partners commanding superior faculty, will not share entire transaction networks with inferior partners as uniqueness is a strategic asset, a source of competitive advantage. Thus, in MLA with large number of structural holes, dyadic ties will be formed on the basis of complementary assets to fill the holes. Thus, exclusive dyads in MLA may mean direct benefit for some partners and indirect benefits for other partners. For example, (see Figure 2) B and C have a direct interface to serve customers; A and B also have direct interface to serve customers, however, $\mathrm{A}$ and $\mathrm{C}$ have indirect interface through $\mathrm{B}$ to provide service to A's customers requiring to 
pass through B to C. Since this is rare for A's customers the cost of a direct interface between $\mathrm{A}$ and $\mathrm{C}$ is higher than sharing the indirect interface through $\mathrm{B}$. In other words, B becomes a broker that saves A transaction costs with $\mathrm{C}$.

There is a dark side to dyadic ties in MLA, namely their potential to block common MLA processes. MLA partners engaged in an advantageous exclusive dyadic sphere may resist common alliance processes that attempt to internalize their unique position for the good of all, raising alliance exit costs. Exit costs rise because of the trade-off between MLA uniqueness and individual firm uniqueness. Retaining strategic flexibility revolves around keeping alliance exit barriers down despite of harmonization processes. On the expectation of high exit costs a partner might be in a better position outside the MLA or in another MLA. A partner in a central position may gain from high intensity (high sunk costs and reversal costs) commonalities acting as lock-in, by internalizing other's unique resources, and control partners in non-central positions. Therefore, the stronger role various dyadic ties play in a multilateral alliance, the greater the resistance to move towards high intensity common alliance processes. $^{8}$

Proposition 2: Partners' variety in MLA facilitates the exploitation of structural holes but impedes high intensity common alliance processes (closure), reinforcing positional strength of individual partners.

\section{Multilevel Embeddedness}

Different levels of embeddedness can be identified within MLA. At the lowest level (above society, the total set of all possible relations) we find transaction networks (arms-length

\footnotetext{
${ }^{8}$ High intensity alliance processes would denote, for example, the creation of central platforms for information systems, without which the firm could not operate.
} 
relations), then alliance networks, and at the highest level MLA relations: with the strength of ties increasing from level to level (see Table 2).

Whereas, multilevel embeddedness opens up a larger network of structural holes, it also invites constraints as each member must reconcile consequences of own actions on others, more so at a high embeddedness level than at a low level. In other words the stronger the ties, the more embedded and constrained the action potential with regard to other partners. Partaking in MLA reduces the flexibility of partners to explore the full transaction network. A growing MLA with increased density (unless fixed number of partners) will involve more territorial overlaps and more compromises, eventually greatly reducing the action potential of partners.

Overembeddedness, being trapped in one's own-net, leads to inflexibility, in other words constraints (Gargiulo \& Benassi, 2000; Uzzi, 1997). We draw a parallel with this notion in how MLA partners are embedded on several levels and over time the higher levels, the more constraining ones, are likely to play a greater role through steadily increasing relational intensity. However, each level implies both opportunities and constraints and the overall balance of the two determines the overall value of belonging to MLA.

Proposition 3. Partners' higher level embeddedness will become more constraining as alliance processes strengthen ties over time, and the ability to bridge structural holes at the lower levels diminishes due to increased alliance density, leading to reduced positional strength of individual partners. 


\section{CONCLUSION}

In this chapter we have proposed a conceptual framework for understanding multilateral alliances (MLA) that involve common alliance processes, dyadic ties, and external transaction networks. Such alliances involve great complexity due to the nature of their multilevel embeddedness. MLA emphasizes a degree of commonality among partners to provide integrated products and services across firm boundaries. Yet, multilevel embeddedness inhibits partners to go beyond low intensity commonalities to manage exit barriers.

MLA partners in a central position can use common alliance processes to raise exit barriers for weaker partners and exercise control over them. Thus MLA managers need to balance a complex set of tensions to derive benefits at the same time that strategic flexibility is maintained. In other words, MLA partners need to balance the benefits derived from the heterogeneity of resources and the homogeneity of MLA products and services, rather than one exclusive of another. Partner variety increases the propensity to exploit structural holes, which can be both dyadic and MLA relational opportunity. However, the more important the external transaction networks as proprietary asset the higher the perceived risk of sharing the asset in the MLA. To put it differently, the more crucial the firms in the external transaction network to a partner's competitive advantage, the lower the action potential on common alliance processes.

From a management viewpoint MLA needs to be understood as complex relationship networks spanning multiple levels: external, dyadic and multilateral. This research suggests a conceptual framework that results in a better understanding of partner behaviour vis-à-vis harmonization of alliance processes. It tells us how sharing of proprietary assets and the progression of common alliance processes can act as barriers to exit for firms, a concern for firms wanting to enter MLA. However, in a situation where MLA is covering several distinctive areas of cooperation, separation of proprietary assets and partner management of 
specific cooperation features becomes a boundary choice question. If the benefit of the alliance relationship is superior to not entering the alliance, yet the risk associated with lockin is high, then it is necessary to ring-fence proprietary assets. By the same token if firms contemplating to join MLA are free to exploit opportunities generated by multilevel embeddedness and can broker between external and internal ties, sharing the external transaction network is less likely to pose a perceived exit barrier, but may still pose a threat to high intensity common alliance processes.

Finally, in MLA there is an inherent paradox, namely the level of perceived entry barriers are reflected in the level of perceived exit barriers. In other words, low exit barriers facilitate alliance formation but act as an inhibitor for progressively stronger common alliance processes. This is because progressive increase in common processes increases sunk costs, inherent in the sharing of proprietary assets, facilitating alliance lock-in. In other words there is an important trade-off between firm- and MLA uniqueness, requiring difficult management choices as MLA relations progress over time.

\section{REFERENCES}

Barnes, J. (1954). Class and committees in a Norwegian island parish. Human Relations 7 , $39-58$.

Baum, J. C., \& Dutton, J. E. (1996). Introduction: The embeddedness of strategy. Advances in Strategic Management 13, 1-15.

Borgatti, S. P., \& Everett, M. G. (1994). Ecological and perfect colorings. Social Networks $16,43-55$.

Burt, R. S. (1992). Structural holes. Cambridge, MA: Harvard University Press.

Burt, R. S. (2001). Structural holes versus network closure as social capital (pp. 31-56). In 
N. Lin, Cook, K. S. and Burt, R. S. (Eds.). Social Capital: Theory and Research. New York, NY: Aldine de Gruyter.

Burt, R.S., \& Knez, M. (1995). Kinds of third-party effects on trust. Rationality and Society 7, 255-292.

Coleman, J.S. (1988). Social capital in the creation of human capital. American Journal of Sociology 94, 95-120.

Dacin, M. T., Ventresca, M. J., \& Beal, B. D. (1999). The embeddedness of organizations: Dialogue \& directions. Journal of Management 25, 317-356.

Das, T. K., \& Teng, B.S. (2000). Instabilities of strategic alliances: An internal tensions perspective. Organization Science 11, 77-101.

Das, T. K., \& Teng, B.S. (2002). Alliance constellations: A social exchange perspective.

Academy of Management Review 27, 445-456.

De Rond, M., \& Bouchikhi, H. (2004). On the dialectics of strategic alliances. Organization Science 15, 56-69.

Doz, Y. L. \& Hamel, G. 1998. Alliance Advantage. Boston, MA: Harvard Business School Press.

Faust, K., (1988). Comparison of methods for positional analysis: Structural and general equivalences. Social Networks 10, 313-341.

Gargiulo, M., \& Benassi, M. (2000). Trapped in your own net? Network cohesion, structural holes, and the adaptations of social capital. Organization Science, 11(2) 183196.

Gomes-Casseres, B. (1996). The Alliance revolution: The new shape of business rivalry. 
Cambridge, MA: Harvard University Press.

Gomes-Casseres, B. (2004). Competing in alliance constellations: A primer for managers. In M. A. Trick, (Ed.) 2004. Global corporate evolution: Looking inward or looking outward? (pp. 43-52). Carnegie Bosch Institute, International Management Series, Volume 4. Pittsburgh, PA: Carnegie Mellon Press.

Granovetter, M. (1973). The strength of weak ties. American Journal of Sociology 78, 1360-1380.

Granovetter, M. (1974). Getting a job: A study of contacts and careers. Cambridge, MA: Harvard University Press.

Granovetter, M. (1985). Economic action and social structure: The problem of embeddedness. American Journal of Sociology 91, 481-510.

Granovetter, M. (1992). Problems of explanation in economic sociology. In N. Nohria \& Eccles, R. (Eds.), Networks and organizations: Structures, form and action (pp. 2556). Boston, MA: Harvard Business School Press.

Gudmundsson, S. V. \& Rhoades, D., (2001). Airline alliance survival analysis: Typology, strategy and duration. Transport Policy 8(3), 209-218.

Gudmundsson, S. V. (2011). An empirical test of the internal tensions perspective of strategic alliances. In T. K. Das (Ed.), Behavioral perspectives on strategic alliances (pp. 157-174). Charlotte, NC: Information Age Publishing.

Gudmundsson, S. V., \& Lechner, C. (2006). Multilateral airline alliances: Balancing strategic constraints and opportunities. Journal of Air Transport Management 12, 153

Gudmundsson, S. V., \& Rhoades, D. (2001). Airline alliance survival analysis: Typology, strategy and duration. Transport Policy 8, 209 
Gudmundsson, S. V., de Boer, E. R. \& Lechner, C., (2002). Integrating frequent flyer programs in multilateral airline alliances. Journal of Air Transport Management 8, 409417.

Gulati, R. (1995). Social structure and alliance formation patterns: A longitudinal analysis. Administrative Science Quarterly 40, 619-652.

Gulati, R., \& Gargiulo, M. (1999). Where do interorganizational networks come from? American Journal of Sociology 104(5), 1439-1493.

Hagedoorn, J. \& Frankort, H. T. W. (2008). The gloomy side of embeddedness: The effects of overembeddedness on inter-firm partnership formation. Network Strategy, Advances in Strategic Management 25, 503-530.

Hagedoorn, J. (2006). Understanding the cross-level embeddedness of interfirm partnership formation. Academy of Management Review 31, 670-680.

Khanna, T. Gulati, R. \& Nohria, N. (1998). The dynamics of learning alliances:

Competition, cooperation and relative scope. Strategic Management Journal 19, 193 210.

Lazzarini S.G. (2007). The impact of membership in competing alliance constellations:

Evidence on the operational performance of global airlines. Strategic Management Journal 28, 345-367

Lazzarini, S.G. (2008). The transition from alliance networks to multilateral alliances in the global airline industry. Brazilian Administrative Review 5(1), 19-36.

Lomi, A. (1995). The population ecology of organizational founding: Location dependence and unobserved heterogeneity. Administrative Science Quarterly 40, 111-144.

Lomi, A. (1997). Markets with hierarchies and network structure of organizational 
communities. The Journal of Management and Governance 1(1), 49-66.

McEvily, B., \& Zaheer, A. (1999). Bridging ties: A source of firm heterogeneity in competitive capabilities. Strategic Management Journal 20, 1133-1156.

Moran, P. (2005). Structural vs. relational embeddedness: Social capital and managerial performance. Strategic Management Journal 26(12), 1129-1151.

Podolny, J. (1994). Market uncertainty and the social character of economic exchange. Administrative Science Quarterly 39(3), 458-483.

Polanyi, K. (1944). The great transformation. New York: Rinehart.

Richardson, G. (1972). The organization of industry. Economic Journal 82, 883-896.

Salancik, G.R. (1995). Wanted: a good network theory of organization. Administrative Science Quarterly 40, 345-349.

Uzzi, B. (1997). Social structure and competition in interfirm networks: The paradox of embeddedness. Administrative Science Quarterly 42, 35 - 67.

Uzzi, B. (1999). Embeddedness in the making of financial capital: how social relations and networks benefit firms seeking financing. American Sociological Review 64, 481-505.

Vanhaverbeke, W., \& Noorderhaven, N. G. (2001). Competition between alliance blocks: The case of the RISC-microprocessor technology. Organisation Studies 22, 1-30.

Winship, C. \& Mandel, N.J. (1983). Roles and positions: A critique and extension of the blockmodeling approach. In S. Leinhardt (Ed.), Sociological Methodology 1983-1984 (pp. 314-344). San Francisco, CA: Jossey-Bass.

Yoshino, M.Y., \& Rangan, U.S., (1995). Strategic alliances: An entrepreneurial approach to globalization. Boston, MA: Harvard Business School Press. 
Table 1. Defining Multi-partner Alliances

\begin{tabular}{|c|c|c|}
\hline Concept & Definition & Reference \\
\hline \multirow[t]{3}{*}{ Multilateral alliance } & $\begin{array}{l}\text { "composed of overarching agreements } \\
\text { applicable to all members of the group." }\end{array}$ & $\begin{array}{l}\text { Dos \& Hamel, (1998), ctd. } \\
\text { in Lazzarini }(2008, \text { p. } 20)\end{array}$ \\
\hline & $\begin{array}{l}\text { "A multilateral alliance has at least three } \\
\text { members who have cooperative relationships } \\
\text { with each other involving elements of } \\
\text { commonality across all partners." }\end{array}$ & $\begin{array}{l}\text { Gudmundsson, Lechner and } \\
\text { De Boer (2002, p. 410) }\end{array}$ \\
\hline & $\begin{array}{l}\text { "formalized multi-partner inter-firm relations } \\
\text { that involve not only a collection of dyads, but } \\
\text { also central organization and common alliance } \\
\text { processes." }\end{array}$ & Used in this chapter. \\
\hline \multicolumn{3}{|l|}{ Constellation } \\
\hline & $\begin{array}{l}\text { "an arena in which members are involved in } \\
\text { generalized social exchanges." }\end{array}$ & Das \& Teng $(2002$, p. 446$)$ \\
\hline & $\begin{array}{l}\text { "a set of firms linked together through } \\
\text { alliances and that competes in a particular } \\
\text { competitive domain." }\end{array}$ & $\begin{array}{l}\text { Gomes-Casseres }(2004, \mathrm{p} \text {. } \\
\text { 44) }\end{array}$ \\
\hline \multirow[t]{4}{*}{ Alliance network } & $\begin{array}{l}\text { "a network consists of all interactions between } \\
\text { organizations in a population" }\end{array}$ & Whetten $(1981$, p. 8) \\
\hline & $\begin{array}{l}\text { "a set of two or more connected business } \\
\text { relationships, in which each exchange relation } \\
\text { is between business firms that are } \\
\text { conceptualized as collective actors" }\end{array}$ & $\begin{array}{l}\text { Anderson, Hakansson \& } \\
\text { Johanson }(1994, \text { p. 4) }\end{array}$ \\
\hline & $\begin{array}{l}\text { "A set of linkages between many relatively } \\
\text { comparable firms... or an international } \\
\text { network of independent local...firms..." }\end{array}$ & Doz \& Hamel (1998, p. 222) \\
\hline & "collection of several alliances" & Das \& Teng (2002, p. 446) \\
\hline
\end{tabular}




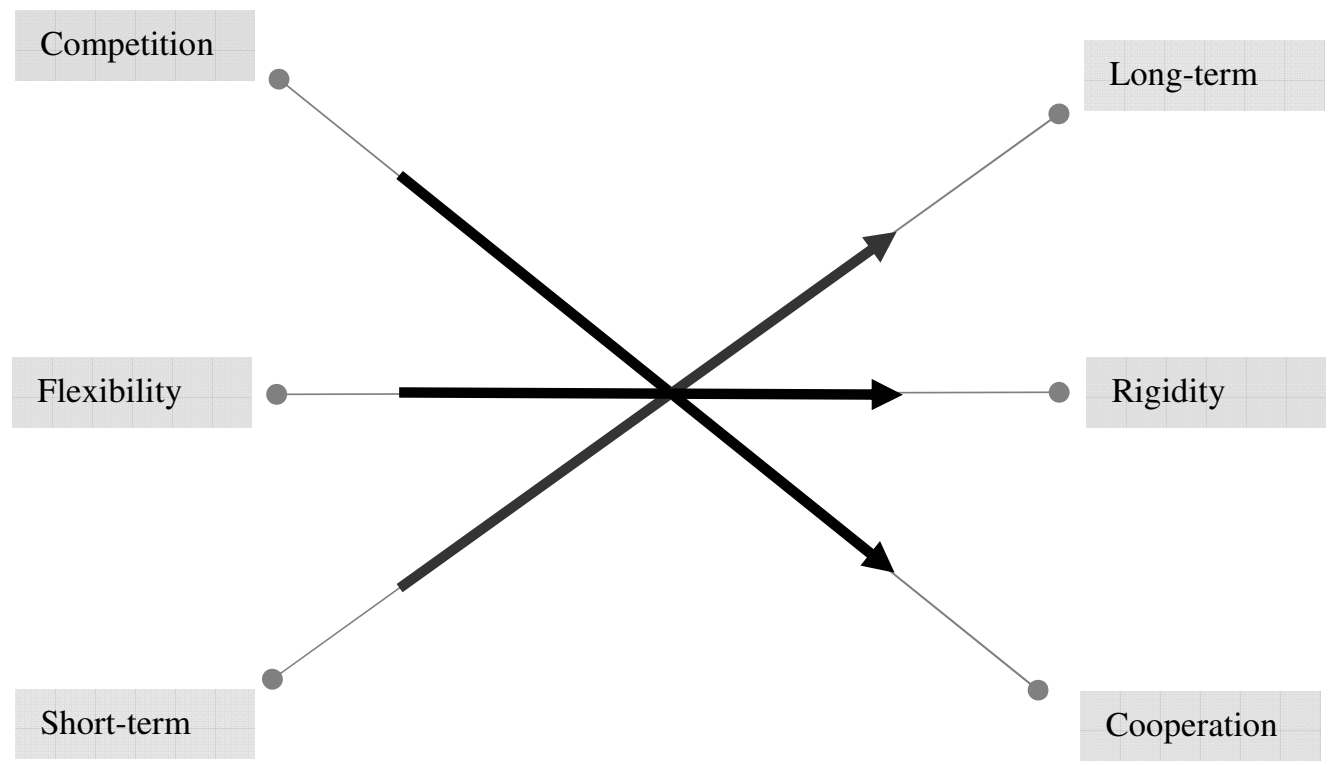

Figure 1. Directional movement along the three tensions when entering MLA 


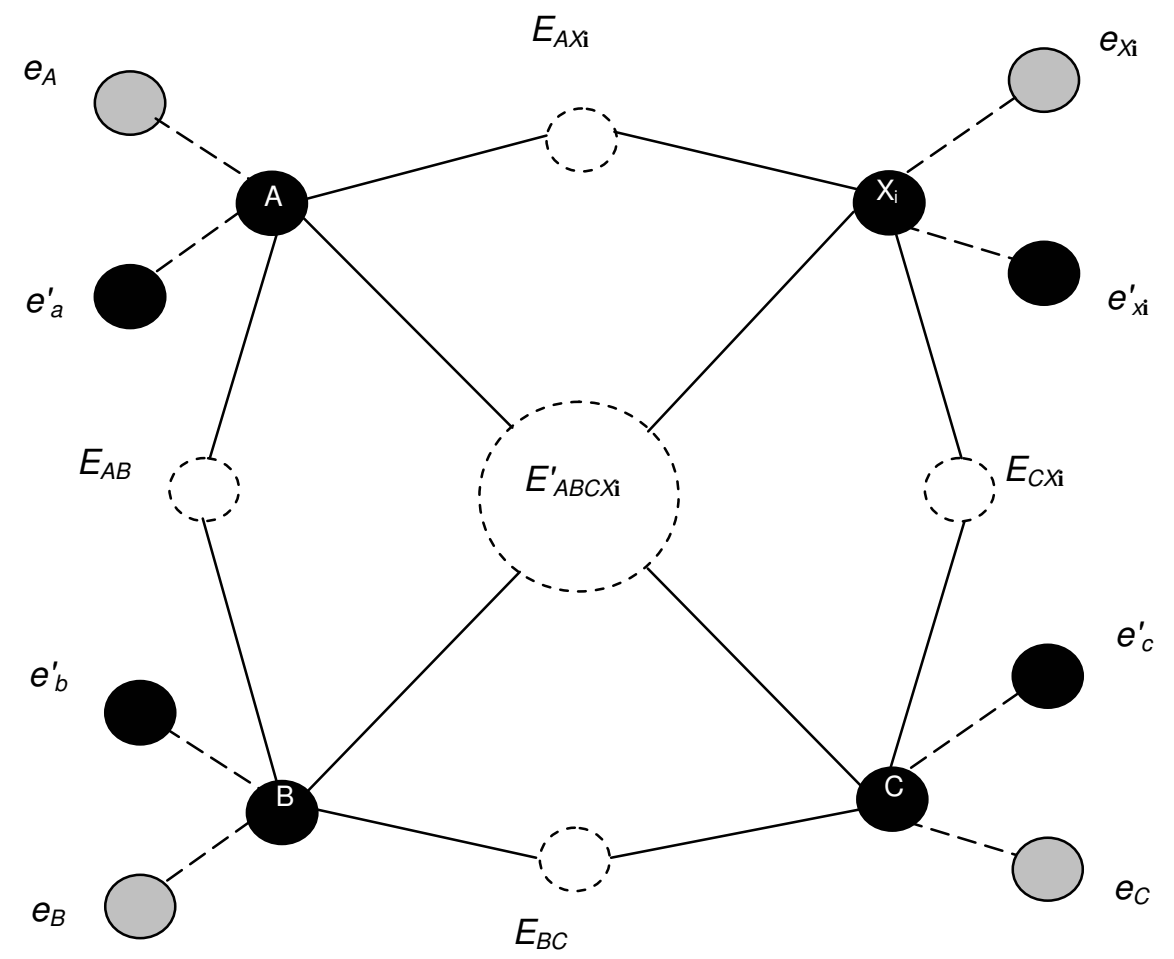

Figure 2. A model of multilevel embeddedness in MLA

Notes: Solid lines denote relations links among firms $\boldsymbol{A} \ldots \boldsymbol{X}_{\mathbf{i}}$, embedded in a multilateral alliance; broken lines denote relations links outside MLA; dotted rings show shared spheres; solid rings show proprietary (ego) spheres; $\boldsymbol{E}(\boldsymbol{E}>2)=$ alliance relations within MLA; $\boldsymbol{i}=1 \ldots \boldsymbol{n}$, partners; $\boldsymbol{e}=$ proprietary (ego) transaction partners outside MLA; $\boldsymbol{e}^{\prime}{ }_{\mathbf{a} . . .} \boldsymbol{e}^{\prime}{ }_{\mathbf{x} \boldsymbol{i}}=$ proprietary (ego) transaction partners shared in MLA; $\boldsymbol{e}_{\boldsymbol{A} \ldots . . .} \mathbf{e}_{\boldsymbol{X} \mathbf{i}}$, = proprietary (ego) transaction partners not shared in MLA; $\boldsymbol{E}_{\boldsymbol{A} \boldsymbol{B} . . .} \boldsymbol{E}_{\boldsymbol{C} X \mathbf{i}}=$ dyadic relations within MLA (dyadic links $\boldsymbol{E}_{\boldsymbol{A} C}$, and $\boldsymbol{E}_{\boldsymbol{B} X \mathbf{i}}$ are omitted to symbolize absence of structural holes); $\boldsymbol{E}^{\prime}{ }_{\boldsymbol{A} \boldsymbol{B} \boldsymbol{C} \boldsymbol{X} \mathbf{i}}=$ common relations within MLA. Multilevel embeddedness is denoted as $\left(\boldsymbol{E}^{\prime} \subseteq \boldsymbol{E} \subseteq\left(\boldsymbol{e}+\boldsymbol{e}^{\prime}\right) \subseteq S\right)$, where $\subseteq=$ subset of, and $\boldsymbol{S}$ =society or set of all possible relations. 
Table 2. Multilevel Embeddedness in Multilateral Alliances

\begin{tabular}{|c|c|c|c|c|}
\hline Embeddedness & Denotation $^{I}$ & Relations Type & Tensions & Spheres \\
\hline $\begin{array}{l}\text { Level } 3\left(\boldsymbol{E}^{\prime}\right) \\
\subseteq^{2}\end{array}$ & $E_{A B C X \mathbf{i}}^{\prime}$ & Multilateral (MLA) & Rigid/cooperative/long-term & Common sphere \\
\hline Level $2(E)$ & $E_{A B \ldots} E_{C X \mathbf{i}}$ & Dyadic (MLA) & $\begin{array}{l}\text { Rigid/cooperative/medium- } \\
\text { term }\end{array}$ & Dyadic sphere \\
\hline $\begin{array}{l}\subseteq \\
\text { Level } 1\left(e+e^{\prime}\right)\end{array}$ & $e_{A \ldots} e_{X \mathbf{i}}$ & $\begin{array}{l}\text { Transaction network } \\
\text { external not-shared }\end{array}$ & $\begin{array}{l}\text { Flexible/competitive/short- } \\
\text { term }\end{array}$ & Dyadic sphere \\
\hline$\subseteq$ & $e_{a \ldots}^{\prime} e_{x \mathrm{i}}^{\prime}$ & $\begin{array}{l}\text { Transaction network } \\
\text { external shared }\end{array}$ & $\begin{array}{l}\text { Flexible/competitive/short- } \\
\text { term }\end{array}$ & Dyadic sphere \\
\hline
\end{tabular}

Notes: ${ }^{1}$ See Figure 2 for explanations. ${ }^{2} \subseteq=$ subset-of. 
Sveinn Vidar GUDMUNDSSON is Professor Strategic Management, Toulouse Business School, France. He was Senior Visiting Fellow, Smith School of Enterprise and the Environment, Oxford University. He earned his BSc, MBA and MSc from Florida Institute of Technology, USA; and a PhD from Cranfield University, United Kingdom. Prior to his academic carrier Sveinn held senior management positions in the airlines and the banking sector. He has received several awards for his research and teaching. His research interests focus on strategic alliances, business performance, entrepreneurship, foresight, electronic marketplaces, low-cost strategies, inter-cultural management, and decision-making and learning through interactive teams. E-mail: s.gudmundsson@esc-toulouse.fr

Christian LECHNER is Professor Strategic Management and Entrepreneurship, and Head of the Research Center for Entrepreneurship and Growth Strategies at Toulouse Business School. He has a diploma in Italian and International Business Studies, from University of Florence, Italy; German Diploma in Business Administration from Ludwig-MaximiliansUniversity, Munich, Germany; Master of Business Administration from University of Georgia, USA; and a PhD in Business Administration, University of Regensburg, Germany. He has spent periods as Visiting Professor at the University of Regensburg, Germany; Rutgers University, USA; Libera Università di Bolzano, Italy; ESSEC Barcelona, Spain; and WHU Germany. His research interests cover entrepreneurship, regional and small firm networks, high-tech clusters, strategic networks, cooperative competition, and growth strategies. E-mail: c.lechner@esc-toulouse.fr

Hans van KRANENBURG is Professor of Corporate Strategy at Radboud University Nijmegen, the Netherlands. He has been a visiting scholar at National Opinion Research Center affiliated with the University of Chicago and visiting professor at Jönköping 
International Business School. He received his BA (Agricultural Economics) from the University of Exeter and his MA (Econometrics) from Tilburg University (the Netherlands). His Ph.D in Econometrics/Industrial Economics is from the Maastricht University. His research interests cover market and nonmarket strategies, industry dynamics, industrial organization, international business, (strategic) behavior of firms and information and communications industries. E-mail: h.vankranenburg@fm.ru.nl 